\title{
The Effect of Cognitive and Metacognitive Writing Strategies on Content of the Iranian Intermediate EFL Learners' Writing
}

\author{
Mehran Rajaee Pitenoee \\ Department of Linguistics and Foreign Languages, Payame Noor University, Rasht, Iran \\ Ahmad Modaberi \\ Department of Linguistics and Foreign Languages, Payame Noor University, Rasht, Iran \\ Elham Movafagh Ardestani \\ Department of Linguistics and Foreign Languages, Payame Noor University, Qum, Iran
}

\begin{abstract}
Writing strategies instruction have become one of the most talked-about topics in the field of language teaching and learning when scholars found that SL/FL writing is believed to be a problem for learners. Cognitive and metacognitive strategies, as two writing strategies, have been widely researched over the past few decades. Among the substantial body of research investigating the effect of cognitive and metacognitive writing strategies, little attention has been given to the effect of cognitive and metacognitive strategies on content of the learners' writing. This experimental investigation is conducted to explore how the cognitive and metacognitive writing strategies can affect the content of the Iranian intermediate learners' writing. For this purpose, 75 intermediate learners were recruited to participate in this study. They were randomly assigned to three groups to form two experimental groups and one control group. Each of the cognitive and metacognitive groups was instructed by one of the cognitive and metacognitive strategies. The findings provide evidence that the intervention favor the experimental groups' learners to create a better content for their writing. The results of this study also indicate that there was significant relationship between cognitive and metacognitive groups. In other words, the metacognitive group outperformed the cognitive one in content of the writing. The implication of this study is to indicate which of the cognitive and metacognitive strategies are most likely to be instructed to students.
\end{abstract}

Index Terms - metacognitive strategy, cognitive strategy, intermediate learners, EFL learners, content, English writing

\section{INTRODUCTION}

In the recent decades, writing strategies has been one of the major interesting research subjects (De Silva, 2015; Rahimi \& Karbalaei, 2016). Flower and Hayes (1981) state, as a most complicated process writing involves a number of metacognitive and cognitive activities such as brainstorming, planning, drafting, and So on. Particular attention was given to cognitive aspects of writing, as Flower and Hayes (1981) have attempted to understand the thought processes underlying the compositions of students (cited in Negari, 2011). According to Omaggio Hadley (1993) Writing requires composing, which implies the ability either to tell or retell pieces of information in the form of narratives or description, or to transform information into new texts, as in expository or argumentative writing. Then, it considered as a continuum of activities that range from the more mechanical or formal aspects of writing down on the one end to the more complex act of composing on the other end. (cited in Negari, 2011)

It is almost certain that training learners how to use language learning strategies help them to be a successful learner. O'Malley and Chamot (1990) told that effective L2/FL learners use learning strategies consciously. Then, students need to utilize the suitable strategies to be a professional writer because a positive correlation can be observed between writing competence and strategy use (Chien, 2012).

As technical writing is considered to be a problem for EFL learners (Harris, Graham, Mason, \& Friedlander, 2008), writing strategies need to be discussed and instructed in writing classrooms to help learners improve their writing performance. For this purpose, the main aim of the current is to examine the effectiveness of cognitive and metacognitive writing strategies on the content of EFLintermediate learners' writing.

\section{REVIEW OF THE RELATED LITERATURE}

Nowadays, being an Effective writer is very important in L2 education. So, writing instruction has become increasingly important in L2 classrooms. For contact and interact with each other, languages and cultures become even more essential. As a result, the ability to speak and write is crucial for educational and personal reasons. Additionally, 
writing is very important in L2 classrooms (Weigle, 2002). So, it is an important part of the communicative language teaching where language is seen as a system of communication rather than an object to be studied. In other words, writing is not used to reinforce repetitions of grammar and vocabulary in modern L2 classrooms but rather it is an important enterprise in and of itself (Weigle, 2002).

Hyland (2003) cited learning how to write is very difficult for both L2 learners and native speakers of English. It means that, to be native speaker of English does not mean that this person knows how to write effectively. Therefore, knowing how to write effectively requires a lot of continuous and specialized instruction for both native speakers and L2 learners of English. Hyland (2003) noted that both learning and teaching of the writing skill is important. In other words, teaching writing plays a very significant role in the field of L2 teaching.

In academic writing composing, analyzing and organizing ideas is sophisticated. Cognitive and metacognitive problems in students 'writing is an issue that they naturally face with. Sturm and Rankin-Erickson (2002) argued that one of advanced academic work in educational settings is composing, and applying various cognitive strategies are parts of the students' difficulties in writing.Sturm and Rankin-Erickson (2002) further stated that strategy instruction is a teaching approach that help students to develop strategies for all process of the writing by dividing the writing tasks and making the sub processes and skills much more explicit.

Graham \& Harris (1996) cite, many teachers tried to influence the course of this development in a relatively straightforward and direct fashion. They might model and explicitly teach the types of strategies used by more successful writers, or might predict routines where writing processes such as planning and revising were expected and strengthened (as cited in Negari, 2011). This view toward explicit teaching of learning strategies has marked a continued investigation into learning processes and support for the communicative philosophy of teaching learners how to learn, and thus become independent and autonomous learners through the use of learning strategies (Wenden, 1991 cited in Negari, 2011). Brown (2000) indicated to the effectiveness of learning strategies in a variety of contexts. Brown mentioned that "...we probe its implications for your teaching methodology in the classroom, specifically, how your language classroom techniques can encourage, build, and sustain effective language-learning strategies in your students" (p.130).

Mayer (2003) identified three due processesfor meaningful learning. These are: attendance, organization, and integration. Learners must pay attention to the relevant and important content, organize the content structurally, and integrate the content into their existing cognitive structure. Strategy teaching can therefore be summarized as teaching learners how to learn, with a view to become independent and autonomous learners. (Mayer, 2003). In the past many believed that learning ability of any person was a function of his intelligence and aptitude, but recently, the role of other non-intrinsic factors were bolded in the process of learning. It is necessary here to clarify exactly what is meant by cognitive and metacognitive strategies as two important learning strategies.Cognitive strategies is defined by Weinstein and Hume (1998) as the behaviors, thoughts, or actions used by the learner in the process of learning to organize and store knowledge and skills, and to apply them easily in the future.Metacognition is our knowledge about our own cognitive processes and how to optimally use them to achieve learning objectives (Biehler\& Snowman, 1993). Metacognitive strategies are used for selecting suitable methods intelligently, supervising on their efficacy, correcting of errors, and if required, changing strategies and replacing them with new ones (Good \&Brophy, 1995 as cited in Maleki, 2005).

Up to now, a number of studies have found that use of cognitive and metacognitive strategies improve learning process (Miller \& Mercer, 1993; Biehler \&Snowman, 1993; Weinstein and Hume, 1998).

Wei. Chen and Adawu (2014) in a study explored how strategy-based instruction (SBI), assisted by multimedia software, can be incorporated to teach beginning-level ESL learners metacognitive writing strategies. Two beginninglevel adult learners participated in a 10-session SBI on planning and organizing strategies. The Cognitive Academic Language Learning Approach (CALLA) was implemented with the aid of graphic organizer software. It was found that technology-supported SBI has brought multiple benefits for the learners. Comparison of the writings before and after SBI indicated that there is noticeable improvement in learners' ability to generate ideas and organize them properly.

Teng (2016) in a study examined the effectiveness of cooperative training strategies in enhancing students' metacognitive skills and therefore their English writing. Towards this, two distinct settings for cooperative training, different in terms of embedded metacognitive instructions, were explored. Results indicated that the cooperative learning condition with embedded metacognitive instructions condition yielded the highest mean scores in writing and regulation of cognition, followed by the cooperative learning condition and the control group.

Panahandeh and Esfandiar (2014) investigated the effects of planning and monitoring skills as metacognitive strategies on Iranian intermediate EFL learners' argumentative writing accuracy. Sixty university students participated in the study. They were randomly assigned to control and experimental groups. The experimental group received metacognitive strategies-based writing instruction whereas the control group received only the routine writing instruction. The results showed that there was a positive effect in the experimental group's writing performance. The findings have implications for pedagogy as well as for research.

Rahimi and Karbalaei (2016) in a study investigated the role of metacognitive strategies training on developing writing skill among Iranian EFL learners. Fifty students participated in the present study. A panel of readers and raters evaluated students writing proficiency, their acquisition, and use of rhetorical modes in their writing products. 
Students' perceptions on writing were measured by a post-treatment questionnaire. The study did not show any significant differences between the mean scores of students` writing narrative and expository textsin Reading/ Writing Inter- face or Writing Process treatments as assessed in holistic evaluations.

Paris (2003) in his study examined the application of cognitive strategy instruction in teaching writing. A writing test was given at the beginning and end of this study to evaluate writing skill development. Self-regulated strategy instruction in writing was implemented in the classroom. Six basic stages of instruction were used to introduce writing strategies. Mnemonics were used to facilitate retention of components of the final writing project. Students were taught to maintain and generalize the use of strategies. Pre-test and post-test writing samples were scored holistically using written descriptors which ranged from 1-Inadequate Command of written language to 6-Superior Command of written language. Results of this study indicated an increase of 1 in the mean scores from the pre-test (2.5) to the post-test (3.55).

More recently, NematTabrizi and Rajaee (2016) attempted to show how cognitive and metacognitive writing strategies can affect the total scores of elementary level learners' writing. They have studied 75 students which were divided into onecontrol group and two experimental groups. Each of the experimental groups was instructed by one of the cognitive and metacognitive writing strategies. The results of this study indicate that both cognitive and metacognitive writing strategies help elementary learners to improve their writing. Furthermore, the results pointed to the metacognitive group superiority over the cognitive one.

Although some research has been carried out on the cognitive and metacognitive writing strategies, there is very little scientific understanding of the effect of cognitive and metacognitive writing strategies on the content of the learners' writing. This was the motivation behind the present study.

\section{RESEARCH QUESTIONS AND HYPOTHESES}

In line with general objectives, the following research questions specifically guide this study:

Q1: Do metacognitive writing strategies have any significant effect on content of Iranian intermediate EFL learners' writing?

Q2: Do cognitive writing strategies have any significant effect on content of Iranian intermediate EFL learners' writing?

Q3: Do cognitive writing strategies have more effect than metacognitive writing strategies on content of Iranian intermediate EFL learners' writing?

Based on the research questions, the following hypotheses are formulated:

H01: Metacognitive writing strategies do not have any significant effect on content of Iranian intermediate EFL learners' writing.

H02: Cognitive writing strategies do not have any significant effect on content of Iranian intermediate EFL learners' writing.

H03: Cognitive writing strategies have more effect than metacognitive writing strategies on content ofIranian intermediate EFLlearners' writing.

\section{METHOD}

\section{A. PARTICIPANTS}

To run this study, 75 EFL learners were recruited to participate from two private language institutes in Golestan, Iran. The students were Persian native speakers. They varied in age from 13 to 17 years. The participants of the study were also randomly selected and divided into three groups. There were 25 students in each of the experimental groups (i.e. cognitive and metacognitive writing strategies) and there were 25 participants in the control group.

\section{B. INSTRUMENTS}

\section{Nelson test}

Nelson English Language Test (Coe \& Fowler, 1976) was conducted to assure that the participants were all at the intermediate level of proficiency. The applied test contained 50 items. The test is set for a $30(60 \%)$ pass mark.

\section{Pre and Post-test Instruments}

The pretest and posttest of writing was employed from Family and Friends 6 (Thumpson and Simmon, 2009). The content validity of the writing tasks were checked by two expertsbefore it was administered to the students. The pretest and the posttest of writing had exactly the same format but different content for reason of eliminating the retention effect that the pretest may have on the subjects' performance on the posttest. The time devoted to learners to write the text was 30 minutes. Additionally, in order to check the reliability of the writing scale, the internal consistency reliability of writing was checked by calculating Cronbach's alpha coefficient and it was found that the reliability of writing pre-test was 0.85 and post-test was 0.80 .

\section{Writing Scoring Criteria}

Jacob's ESL composition profile (Jacobs, Zingraf, Wormuth, Hartfiel\&Hughey, 1981) has been employed to evaluate the content of writing. The response scales range from excellent to poor. The validity of scale is widely acknowledged 
through a considerable number of composition researchers and raters. All the writing sheets were marked by two teachersand if the raters' given scores were different, the mean of the two scores werecalculated.

\section{PROCEDURE}

In the first phase of the study, a standard version of Nelson test was administered to total population of 170 students to make sure that the students were all at the same level of English language proficiency. The researchers couldrandomly select 75 participants from among a total number of 110 learners whose scores fell one standard deviation (1SD) above and below the mean.

Thereafter, the writing composition pretest was administered to all subjects one week prior to the treatment to ensure their homogeneity prior the beginning of the study. Following this, the treatment period started and lasted for 8 sessions. The control group learners were provided with the same course content, although they received almost no specific training on the strategies of writing. Therefore, learners in all classes experienced the same condition and the only focused difference was the cognitive (i.e. revising, text generating, and resourcing) and metacognitive (i.e. selfinitiation, planning, and monitoring and evaluation) strategies instruction in experimental groups.

Then, the post-test of writing was administered to all subjects in control and experimental groups to assess the amount of change on the content of the learners' writing from the pre-test to the post-test for each group separately. Finally, the results and findings were reported.

\section{RESULT}

\section{A. INTER-RATER RELIABILITY}

Inter-rater correlation coefficient was calculated for pretest and posttest of all three groups because "rating on writing test in academic context varies considerably" (Hamp-Lyons, 2003, p. 174). The results, as indicated in Table 1, revealed a high positive correlation between the rating of raters in both pre- and posttests, so there is no significant difference between the scores of the two teachers:

TABLE 1.

INTER-RATER CORRELATION OF RATERS

\begin{tabular}{llll}
\hline & & $\mathrm{N}$ & Correlation \\
\hline Pair 1 & A.pre.C \& B.pre.C & 25 & .96 \\
Pair 2 & A.pos.C \& B.pos.C & 25 & .94 \\
Pair 3 & A.pre.M \& B.pre.M & 25 & .97 \\
Pair 4 & A.pos.M \& B.pos.M & 25 & .98 \\
Pair 5 & A.pre.Cog \& B.pre.Cog & 25 & .95 \\
Pair 6 & A.pos.Cog \& B.pos.Cog & 25 & .96 \\
\hline Note. $A=$ Rater A; $B=$ Rater B; $M=$ Metacognitive group; Cog $=$ Cognitive group; C = Control group
\end{tabular}

\section{B. PRETEST OF WRITING}

Table 2 presents the descriptive statistics obtained from both experimental groups and control group in pre-test of writing. As can be seen from the table, the cognitive group reported significantly more mean $(M=20.4, S D=2.76)$ than the other two groups. This was followed by the metacognitive $(\mathrm{M}=20.08, \mathrm{SD}=2.51)$ and control $(\mathrm{M}=19.92, \mathrm{SD}$ $=2.54$ ) groups.

TABLE 2.

DESCRIPTIVE STATISTICS, PRETEST OF WRITING BY GROUPS

\begin{tabular}{|c|c|c|c|c|c|c|c|c|}
\hline & \multirow[b]{2}{*}{$\mathrm{N}$} & \multirow[b]{2}{*}{ Mean } & \multirow{2}{*}{$\begin{array}{l}\text { Std. } \\
\text { Deviation }\end{array}$} & \multirow[b]{2}{*}{ Std. Error } & \multicolumn{2}{|c|}{$\begin{array}{l}95 \% \text { Confidence Interval for } \\
\text { Mean }\end{array}$} & \multirow{2}{*}{ Minimu } & \multirow{2}{*}{$\begin{array}{l}\text { Maximu } \\
\mathrm{m}\end{array}$} \\
\hline & & & & & Lower Bound & Upper Bound & & \\
\hline control & 25 & 19.92 & 2.548 & .510 & 18.87 & 20.97 & 16 & 25 \\
\hline metacognitive & 25 & 20.08 & 2.515 & .503 & 19.04 & 21.12 & 16 & 25 \\
\hline cognitive & 25 & 20.40 & 2.769 & .554 & 19.26 & 21.54 & 16 & 25 \\
\hline Total & 75 & 20.13 & 2.585 & .299 & 19.54 & 20.73 & 16 & 25 \\
\hline
\end{tabular}

As shown in table 3, no significant difference at the $\mathrm{P}>.05$ level was seen in scores of the pretest writing for the three groups: $\mathrm{F}(2,72)=.219, \mathrm{P}=.8$. Therefore, it can be concluded that they enjoyed the same level of writing ability prior to the main study.

TABLE 3 .

ONE WAY ANOVA ON PRE-TEST BY GROUPS

\begin{tabular}{llllll}
\hline Sum of Squares & & df & Mean Square & F & Sig. \\
\hline Between Groups & 2.987 & 2 & 1.493 & .219 & .804 \\
Within Groups & 491.680 & 72 & 6.829 & & \\
Total & 494.667 & 74 & & & \\
\hline
\end{tabular}




\section{Post Test of WRIting}

A one-way ANOVA was used to analyze the three groups' means on writing and to assess how different sorts of strategies can affect the content of the learners' writing. It is apparent from table 4 that the metacognitive strategy group $(\mathrm{M}=26.84, \mathrm{SD}=1.17)$ had the highest mean on the post-test of writing. This was followed by the cognitive strategy group $(\mathrm{M}=25.04, \mathrm{SD}=1.36)$ and control group $(\mathrm{M}=21.44, \mathrm{SD}=2.41)$.

TABLE 4.

DESCRIPTIVE STATISTICS; POSTTEST OF WRITING BY GROUPS

\begin{tabular}{|c|c|c|c|c|c|c|c|c|}
\hline & $\mathrm{N}$ & Mean & Std. Deviation & Std. Error & \multicolumn{2}{|c|}{$95 \%$ Confidence Interval for Mean } & Minimum & Maximum \\
\hline control & 25 & 21.44 & 2.417 & .483 & 20.44 & 22.44 & 17 & 26 \\
\hline cognitive & 25 & 25.04 & 1.369 & .274 & 24.48 & 25.60 & 22 & 27 \\
\hline Total & 75 & 24.44 & 2.839 & .328 & 23.79 & 25.09 & 17 & 29 \\
\hline
\end{tabular}

Table 5 provides that there was a statistically significant difference at the $\mathrm{P}<.05$ level in post test writing scores for the three groups: $\mathrm{F}(2,72)=.6 .22, \mathrm{P}=.0$.

TABLE 5.

ONE-WAY ANOVA; POST-TEST OF WRITING BY GROUPS

\begin{tabular}{llllll}
\hline Sum of Squares & & df & Mean Square & F & Sig. \\
\hline Between Groups & 378.000 & 2 & 189.000 & $6.228 \mathrm{E} 1$ & .000 \\
Within Groups & 218.480 & 72 & 3.034 & & \\
Total & 596.480 & 74 & & & \\
\hline
\end{tabular}

Post hoc comparisons using the Tukey HSD test, as demonstrated in table 6, indicated that all the values are less than .05. There is a statistically significant difference between the metacognitive group and cognitive group (P $=.001<.05)$. Furthermore, a significant difference was found between the metacognitive and control groups' scores $(\mathrm{P}$ $=.0<.05)$. Additionally, a significant difference was observed between thecognitive and control groups' scores.

TABLE 6.

MULTIPLE COMPARISONS

\begin{tabular}{lllllll}
\hline & \multicolumn{2}{c}{ Mean Difference (I- } & & \multicolumn{2}{c}{$95 \%$ Confidence Interval } \\
\cline { 5 - 7 }$(\mathrm{I})$ groups & $(\mathrm{J})$ groups & $\mathrm{J})$ & Std. Error & Sig. & Lower Bound & Upper Bound \\
\hline control & metacognitive & $-5.400^{*}$ & .493 & .000 & -6.58 & -4.22 \\
& cognitive & $-3.600^{*}$ & .493 & .000 & -4.78 & -2.42 \\
\hline metacognitive & control & $5.400^{*}$ & .493 & .000 & 4.22 & 6.58 \\
& cognitive & $1.800^{*}$ & .493 & .001 & .62 & 2.98 \\
\hline cognitive & control & $3.600^{*}$ & .493 & .000 & 2.42 & 4.78 \\
& metacognitive & $-1.800^{*}$ & .493 & .001 & -2.98 & -.62 \\
\hline
\end{tabular}

Together these results report that the first two hypotheses are rejected because both metacognitive and cognitive strategies bring about profound effect on the content of Iranian intermediate EFL learners' writing. Furthermore, the third hypothesis is also rejected because metacognitive strategy exerts more remarkable effects on the content of Iranian intermediate EFL learners' writing.

\section{DiscusSION AND CONCLUSION}

Regarding the first and second research questions and comparing the learners' posttest and pretest scores in experimental groups and control group, the researchers found that the content of the experimental groups' writing have further progressed after writing strategies instruction over the semester. The results support the idea of De Silva (2015) and Ong and Zhang (2013) who concluded that writing strategy instruction contribute toward enhancing the quality of the learners' writing. Both cognitive and metacognitive writing strategies help learners to go one step further in their writing and have better perception of the content of their writing. To shed light on this issue, Mayer (1998) found that both cognitive and metacognitive strategies improve quality of the learners' writing performance because as Bloom (2008) stated, right writing strategies help writers to become more autonomous and help them to perceive, assess, and improve their learning and writing better.

Finally, the third research question seeks to find out which of the cognitive and metacognitive writing strategies help elementary EFL learners to create a better content for their writings. The comparison of the post-test scores of the experimental groups revealed that there was significant difference between the performances of the two groups, holding that there was no significant difference between the performances of the two groups in the pretest. That is, 
metacognitive writing strategies led to a higher level of writing content, although the two techniques were equally effective in improving the Iranian EFL learners' writing performance. Zimmerman and Schunt (2011) found that metacognitive strategies help learners to reach desirable goals and have better control over their behavior and their learning which is in good agreement with the results of the present study. The present finding also support Gombert (1993) study which concluded that the metacognitive strategies promote the communicative competence of the learners' writing.

Consistent with findings by O'Malley and Chamot (1990), we found that metacognitive group learners' higher level of thinking, planning, monitoring, and evaluating are among the key factors influencing the effectiveness of the metacognitive writing strategies. By the same token, Schraw (2009) reported that metacognitive strategies instruction aid learners to enhance theirability to monitor and judge their own performance. In addition to the stated reasons for the metacognitive group superiority, self regulation can also be considered as the other significant factor. Self regulation as one of the advantages of metacognitive strategies instruction contribute greatly toward transferring skills, knowledge, and strategies across contexts and situations (Azevedo \& witherspoon, 2009; Veenman, Van Hout-Wlters, \&Afflerbach, 2006).

Therefore, learners in different age groups and contexts take advantage of metacognitive strategy to develop their writing performance (Nguyen \&Gu, 2013). This can be confirmed in Abdollahzadeh (2010), NematTabrizi and Rajaee (2016), panahandeh and Esfandiar (2014), and Teng (2016) investigations which explored learners in different age groups and contexts.

In summary, therefore, the present study has revealed that both cognitive and metacognitive strategies can be valuable and improve the content quality of Iranian intermediate learners' writing. Furthermore, the results of this investigation also show that metacognitive group outperformed the cognitive one.

The study has gone some way towards enhancing our understanding of the effect of cognitive and metacognitive writing strategies instruction on content of intermediate learners' writing. The analysis of cognitive and metacognitive strategies instruction undertaken here, also, has extended our knowledge of writing strategy instruction.

The findings of this investigation complement those of earlier studies. The findings of this research provide insights for learners in demonstrating the importance of employing writing strategies to write better and improve the quality content of their writing. The practical implication of this study is the contribution to materials and syllabus design to indicate which of cognitive and metacognitive strategies are most likely to be instructed to students.

Further studies, which take these variables into account, will need to be undertaken. 1) Further research could be conducted to determine the effectiveness of cognitive and metacognitive writing strategies on content of the ESL learners' writing. 2) Further studies regarding the role of cognitive and metacognitive writing strategies on organization, vocabulary, language use, and mechanics of EFL/ESL learners' writing would also be worthwhile. 3) More research is required to determine the efficacy of cognitive and metacognitive writing strategies on content of the advanced learners' writing.

\section{REFERENCES}

[1] Abdollahzadeh, E. (2010). Undergraduate Iranian EFL learners' use of writing strategies. Writing and Pedagogy, 2(1), 65-90.

[2] Ausubel, D. P. (2000). The acquisition and retention of Knowledge: a cognitive view. Boston: Kluwer Academic Publishers.

[3] Azevedo, R., \& Witherspoon, A. M. (2009). Self-regulated use of hypermedia. In A. Graesser, J. Dunlosky, \& D. Hacker (Eds.), Handbook of metacognition ineducation (pp. 319-339). Mahwah, NJ: Erlbaum.

[4] Biehler, \& Snowman, J. (1993). Psychology applied to teaching. Houghton: Mifflin.

[5] Bloom, M. (2008). Second language composition in independent settings: Supporting the writing process with cognitive strategies. In S. Hurd \& T. Lewis (eds.), Language learning strategies in independent settings (pp. 103-118). Tonawanda, NY: Multilingual Matters.

[6] Brown, H. D. (2000). Principles of Language Learning and Teaching. (Fourth Edition) New York: Longman.

[7] Chien, S. C. (2012). Students' use of writing strategies and their English writing achievements in Taiwan. The Asia Pacific Journal of Education, 32(1), 93-112.

[8] De Silva, R. (2015). Writing strategy instruction: Its impact on writing in a second language for academic purposes. Language Teaching Research, 19(3), 301-323.

[9] Flower, L. \& Hayes, J. R. (1981). Plans that guide the composing process. In C. H. Frederiksen, \& J. F.Gombert, J. E. (1993). Metacognition, metalanguage and metapragmatics. International Journal of Psychology, 28, 571-580.

[10] Hamp-Lyons, L. (2003). Writing teacher as assessor of writing. In B. Kroll (Ed.), Exploring the dynamics of second language writing (pp. 162-189). Cambridge, UK: Cambridge University Press.

[11] Harris, K., Graham, S., Mason, L., \& Friedlander, B. (2008). Powerful writing strategies forall students. Baltimore, MD: Paul H. Brookes.

[12] Hyland, K. (2003). Second Language Writing. Cambridge: Cambridge University Press.

[13] Maleki, B. (2005). Effect of instructing cognitive and metacognitive strategies on development of course contents learning and memorization. New Cognitive Findings, 3.225-236.

[14] Mayer, R. E. (2003). The promise of educational psychology. teaching for meaningful learning. Upper Saddle River, NJ: Merrill.

[15] Mayer, R. E. (1998). Cognitive, metacognitive, and motivational aspects of problem solving. Instructional science, $26,49-63$.

[16] Miller, S. P., \& Mercer. C. D. (1993). Using a graduated word problem sequence to promote problem-solving skill, learning. Disability Research and Practice, 8(3), 174-196. 
[17] Negari, G. M. (2011). A study on strategy instruction and EFL learners' writing skill. International Journal of English Linguistics, 1(2), 299-307.

[18] NematTabrizi, A. R., \&Rajaee, M. (2016). The effect of metacognitive and cognitive writing strategies on Iranian elementary learners' writing achievement. International Journal of Learning and Development, 6(3), 216-229.

[19] Nguyen, L. T. C., \&Gu, Y. Q. (2013). Strategy-based instruction: a learner-focused approach to developing learner autonomy. Language Teaching Research, 17, 9-30.

[20] Omaggio Hadley, A. (1993). Teaching language in context. Boston: Heinle \& Heinle.

[21] O'Malley, J. M., \&Chamot, A. U. (1990). Learning strategies in second language acquisition. Cambridge, UK: Cambridge University Press.

[22] Ong, J., \& Zhang, L. J. (2013). Effects of the manipulation of cognitive processes on EFL writers' text quality. TESOL Quarterly, 47(2), 375-398.

[23] Panahandeh, E., \&Esfandiari, sh. (2014). The Effect of Planning and Monitoring as Metacognitive Strategies on Iranian EFL Learners' Argumentative Writing Accuracy. International Conference on Current Trends in ELT, 98, 1409 - 1416.

[24] Paris, A.A. (2003). Cognitive writing strategies. Disability and Equity in Education Commons, 1(2), 115-128.

[25] Rahimi,F.,\& Karbalaei, A.(2016). The Role of Metacognitive Strategies Training on Developing Writing Skill among Iranian EFL learners. Journal of Current Research in Science, 1, 327-341.

[26] Schraw, G. (2009). A conceptual analysis of five measures of metacognitive monitoring. Metacognition and learning, 4(1), 3345.

[27] Sturm, J. \& Rankin-Erickson, J. (2002). Effects of hand-drawn and computer generated concept mapping on the expository writing of middle school students with learning disabilities. Learning Disabilities Research and Practice, 17(2), 124-139.

[28] Teng, F. (2016). Immediate and delayed effects of embedded metacognitive instruction on Chinese EFL students' English writing and regulation of cognition. Thinking Skills and Creativity, 22, 289-302.

[29] Veenman, M., Van Hout-Wolters, B., \&Afflerbach, P. (2006). Metacognition and learning: Conceptual and methodological considerations. Metacognition andLearning, 1, 3-14.

[30] Wei, J., Chen, J., \&Adawu, A. (2014).Teaching ESL Beginners Metacognitive Writing Strategies through Multimedia Software. The CATESOL Journal, 26(1), 60-75.

[31] Weigle, S. C. (2002). Assessing writing. Cambridge: Cambridge University Press

[32] Weinstein, C. E, \& Hume, L. M. (1998). Study strategies for lifelong learning. Washington, D.C.: American Psychology Association.

[33] Zimmerman, B. J., \& Schunk, D. H. (2011). Handbook of self-regulation of learning and performance. New York: Routledge.

Mehran Rajaee Pitenoee is MA graduate in TEFL at Payame Noor University. He got his B.A in English Literature from Golestan University, Iran. He has been the principle and instructor of Danesh Language institute in Golestan, Iran. His areas of interest include Language teaching, teaching of specific skills, and testing and evaluation.

Ahmad Modaberi is MA graduate in TEFL at Payame Noor University. His areas of interest include Language teaching, teaching of specific skills, and testing and evaluation.

Elham Movafagh Ardestani is MA student in TEFL at Payame Noor University. Her areas of interest include Language teaching, teaching of specific skills, and testing and evaluation. 